Review Paper

\title{
Functionalization methods of SBA-15 mesoporous molecular sieve: a brief overview
}

\author{
F. das C. M. da Silva ${ }^{1}$ (1) - M. J. dos S. Costa $^{2}$ - L. K. R. da Silva ${ }^{1}$ - A. M. Batista ${ }^{3}$ - G. E. da Luz Jr. ${ }^{2}$
}

(c) Springer Nature Switzerland AG 2019

\begin{abstract}
SBA-15 molecular mesoporous sieve has attracted great interest of researchers since its discovery in 1998, owing large area surface, well-defined pores, uniform pore size, high thermal and hydrothermal stability, well-defined pore structure and ability to be functionalized with diverse metal oxides (active phase of catalyst). This work contains a brief review of the main SBA-15 functionalization methods: direct synthesis, post-synthesis or post-grafting, deposition-precipitation, graft hybrid, colloid immobilization and nanoparticle encapsulation showing the advantages and disadvantages of each. We also approach some synthetic strategies to overcome the shortcomings of the mentioned methods, as well as some parameters to choose the best method. Here, we showed that these methods don't provide the functionalization of SBA-15 keeping all the peculiar properties of support and that the new strategies or alternatives routes are important to overcome some challenges of the functionalization of SBA-15. This is a challenging point that needs to be further explored by promoting greater advances in materials science and catalysis.
\end{abstract}

Keywords Functionalization methods $\cdot$ SBA-15 $\cdot$ Metal oxides $\cdot$ Advantages

\section{Introduction}

Porous materials are relevant owing to large surface area, uniform pore size, well defined pores and the potential for functionalization with several chemical. International Union of Pure and Applied Chemistry classifies porous materials in three groups: microporous (pore size $<2 \mathrm{~nm}$ ), mesoporous (2-50 nm) and macroporous (> $50 \mathrm{~nm}$ ) [1-4]. Since 1990, mesoporous silica has become a significant class of ordered materials widely studied. Two types of mesoporous silica are described in the literature: MCM-41 and SBA-15 materials. In 1992, Mobil Corporation researchers discovered the family M41S with several members of which MCM-41 is recognized by properties such as: high surface area $\left(>800 \mathrm{~m}^{2} \mathrm{~g}^{-1}\right)$, well-defined pores, uniform pore size distribution, pore diameter from 2 to $10 \mathrm{~nm}$ and adjustable pore diameter [5-8]. However, SBA-15 mesoporous silica is favorite because possesses surface area $\left(600-1000 \mathrm{~m}^{2} \mathrm{~g}^{-1}\right)$, large pore volume (up to $2.5 \mathrm{~cm}^{3}$ $\mathrm{g}^{-1}$ ), pore diameter ranging from 2 to $30 \mathrm{~nm}$ and thermal and hydrothermal stability higher than MCM-41 [9-11]. Moreover, it has great potential as support for the active phase of heterogeneous catalysts and easy diffusion due to minimizing obstruction by pore diameter adjustment $[5,9,10]$.

Zhao and coworkers synthesized SBA-15 (Santa Barbara Amorphous of number 15), in 1998, at the University of California in the United States. It is a mesoporous sieve, silica-based, with unidirectional and hexagonally organized pore structure. They synthesized SBA-15 using as structure-directing agent, the amphiphilic triblock copolymer (Pluronic P123, (poly (ethylene oxide)-block-poly (propylene oxide)-block-poly (ethylene oxide), $\mathrm{EO}_{20} \mathrm{PO}_{70} \mathrm{EO}_{20}$ ) under acidic conditions [11, 12]. SBA-15 possesses a

F. das C. M. da Silva, fmarquesilva@hotmail.com | 'Department of Chemistry, Federal University of Piaui, Teresina, PI 64049-550, Brazil. ${ }^{2}$ GERATEC-CCN-DQ, State University of Piaui, João Cabral S/N, Teresina, PI 64002-150, Brazil. ${ }^{3}$ Centro de Ciências Naturais e Humanas, Federal University of ABC, Av. dos Estados 5001, Santo André, SP 09210-580, Brazil.

SN Applied Sciences (2019) 1:654 | https://doi.org/10.1007/s42452-019-0677-z 
defined pore framework containing cylindrical and parallel mesopores accompanied or not by disordered micropores or mesopores located in the silica wall [12-15].

Synthesis of SBA-15 in general involves dissolving of amphiphilic triblock copolymer in acidic solution, addition of the silica source and hydrothermal treatment. Dissolution of the amphiphilic triblock copolymer occurs at mild temperatures $\left(\sim 40^{\circ} \mathrm{C}\right)$ in acidic medium under agitation; after $2 \mathrm{~h}$ the silica source is added by keeping the systems under the same conditions $\left(40^{\circ} \mathrm{C}\right.$ and under stirring) for $24 \mathrm{~h}$. Subsequently, the hydrothermal treatment is realized at $100{ }^{\circ} \mathrm{C}$ for $48 \mathrm{~h}$. The formed product is cooled to room temperature, filtered, washed with water, dried and calcined at temperatures ranging from 500 to $550^{\circ} \mathrm{C}$ for $5 \mathrm{~h} \mathrm{[11].}$

As for the surfactant, the pluronic triblock copolymer P123 is used to synthesize the SBA-15, because it has a low ratio $E O / P O$, providing the formation of micelles that generate the desired structure of the SBA-15, besides having commercial availability, low cost and biodegradability [16]. As a source of silica, tetraethyl orthosilicate (TEOS) is used because it produces a high purity material and facilitates doping with any material due to low temperatures involved [15-17].

SBA-15 has classified as inert support, although this classification it is not absolute, it serves only as a support to disperse the metallic oxides [14]. This support with remarkable properties, such as well-defined pores, good thermal and hydrothermal stability, uniform pore size distribution, pore diameter from 2 to $10 \mathrm{~nm}$ and high surface area aroused much interest to anchor nanoparticles or metallic oxides $[12,14,15,18]$. Functionalized SBA-15 has several applications, such as: catalysis reaction [19-21], wastewater treatment [22-24], biorefinery production [25], drug deliver [26, 27], $\mathrm{CO}_{2}$ adsorption
[28], photodegradation [36]. The multi-functionization modified SBA-15 has been widely used in adsorption, separation and catalysis [10]. Many studies have focused on the properties and applications of SBA-15 and SBA-15 functionalized as it is presented on Table 1.

Table 1 illustrates the great interest of the scientific community to functionalize SBA-15. It is also highlights the active phase diversity used for functionalization, as well as highlights the applications in catalysis. The synthesis methodology reported in Table 1 indicates that the direct synthesis and post-synthesis methods are the most common, since the sol-gel, pH-adjusting and hydrothermal methods are only adaptations of the direct synthesis method and wet impregnation, incipient wetness impregnation and two-solvents are post-synthesis adaptations. So, in this review we don't describe specifically about the methods sol-gel, $\mathrm{pH}$-adjusting, Hydrothermal and two-solvents.

Despite of the interest of the scientific community and researches accomplished, the functionalization of SBA-15 is challenging task because the heteroatoms can be introduced into the silica wall by replacing $\mathrm{Si}^{4+}$, within the mesopores or on the outer surface and modify the original properties of the support [15]. Literature report several methods of SBA-15 functionalization such as: direct synthesis or "one pot" procedure [25, 38-41], wetness impregnation [40, 42-44], deposition-precipitation (DP) [45-47], graft hybrid (GH) [48, 49], colloid immobilization (Cl) [50-53], nanoparticles encapsulation (NE) $[54,55]$. We briefly reviewed already mentioned methods of SBA-15 functionalization, because it is are the most reported in the literature, to verify if such methods are satisfactory or if we need of new functionalization method/strategies.

Table 1 Functionalization of SBA-15 with various metals to potentialize its application in catalysis

\begin{tabular}{lllll}
\hline Metal & Precursors & Method & Application & Ref. \\
\hline $\mathrm{Al}$ & Aluminum isopropoxide & Sol-gel & Transesterification of tricaprylin & [19] \\
$\mathrm{Ga}$ & Gallium nitrate & pH-adjusting & Alkylation of 1,2-dihydroxybenzene (DHB) & [20] \\
$\mathrm{Ti}$ & Titanium tetraisopropoxide & Direct synthesis & Hydrogen adsorption & [21] \\
$\mathrm{Zr}$ & Zirconium & Direct synthesis & CO $_{2}$ adsorption & [28] \\
$\mathrm{V}$ & Ammonium vanadate & Wet impregnation & Propane oxidative dehydrogenation \\
$\mathrm{Nb}$ & Niobium oxalate & Direct synthesis & Oxidations \\
$\mathrm{Cr}$ & Dichroic trioxide & Hydrothermal & Oxidation of diphenylmethane \\
$\mathrm{Mo}$ & Peroxo Mo solution & Impregnation & Propane photo-oxidation \\
$\mathrm{Fe}$ & Ferric nitrate & Hydrothermal & Ozonation \\
$\mathrm{Ru}$ & Ruthenium chloride & Two-solvents & Hydrogenation \\
$\mathrm{Au}$ and $\mathrm{Co}$ & Chlorauric acid and cobalt nitrate & Incipient wetness impregnation & Oxidation of toluene \\
$\mathrm{Cu}$ and $\mathrm{Zn}$ & Nitrate copper and nitrate zinc & Two-solvents & Photodegradation \\
$\mathrm{Sn}$ and $\mathrm{Pt}$ & Tin chloride and chloroplatinic acid & Direct synthesis and impregnation & Dehydrogenation \\
\hline
\end{tabular}




\section{Main SBA-15 functionalization methods}

\subsection{Direct synthesis method}

Direct synthesis or "one-pot" method consists in the insertion of the precursor source of the metal in the gel synthesis support, as the co-condensation of the transition metal precursors and silicon occurs during the formation of the silica mesostructure. Generally, a synthetic gel is formed following a molar composition: a TEOS/b precursor metal/c P123/d HCl/e $\mathrm{H}_{2} \mathrm{O}$ (a, b, c, d and e are mole numbers of each species). This method involves the following steps: dissolution of the species under acidic conditions, agitation and mild temperatures; ageing at the same dissolution conditions (mild temperatures and controlled stirring); hydrothermal treatment (generally at $100^{\circ} \mathrm{C}$ ), filtration, washing, drying and calcination as reported in literature $[38,40,56,57]$. Scheme 1 shows the general steps of the functionalization of SBA-15 by the direct synthesis and impregnation method.

This method has the advantage of promoting a strong interaction between the embedded metal and SBA-15 support. However, this interaction alters the properties of the SBA-15 mesostructure during the synthesis process, reducing the surface area and diameter of the pores, in addition it presents low rate of incorporation of metal due to the high solubility of their precursors. [57].

\subsection{Post-synthesis or post-grafting method}

This method involves two routes: incipient wetness impregnation and wet impregnation. The difference between mentioned routes is the volume of the solvent used to moisten the support and the evaporation step. Incipient wetness impregnation uses the minimum volume to moisten the support (solvent volume equals the volume of the carrier pores) not requiring the evaporation step; while in wet impregnation, evaporation is necessary to eliminate the excess volume of the solvent containing the active sites [58].

This method is one of the most commonly used when the species to be inserted into the SBA- 15 remain in cationic forms under acidic conditions, similar to those used in the synthesis of SBA-15, for example Ga and Al at acidic $\mathrm{pH}(\sim 1)$ do not condense [42]. Another advantage in
Scheme 1 Main steps of SBA15 functionalization by synthesis direct and post-synthesis methods, respectively $[5,57]$

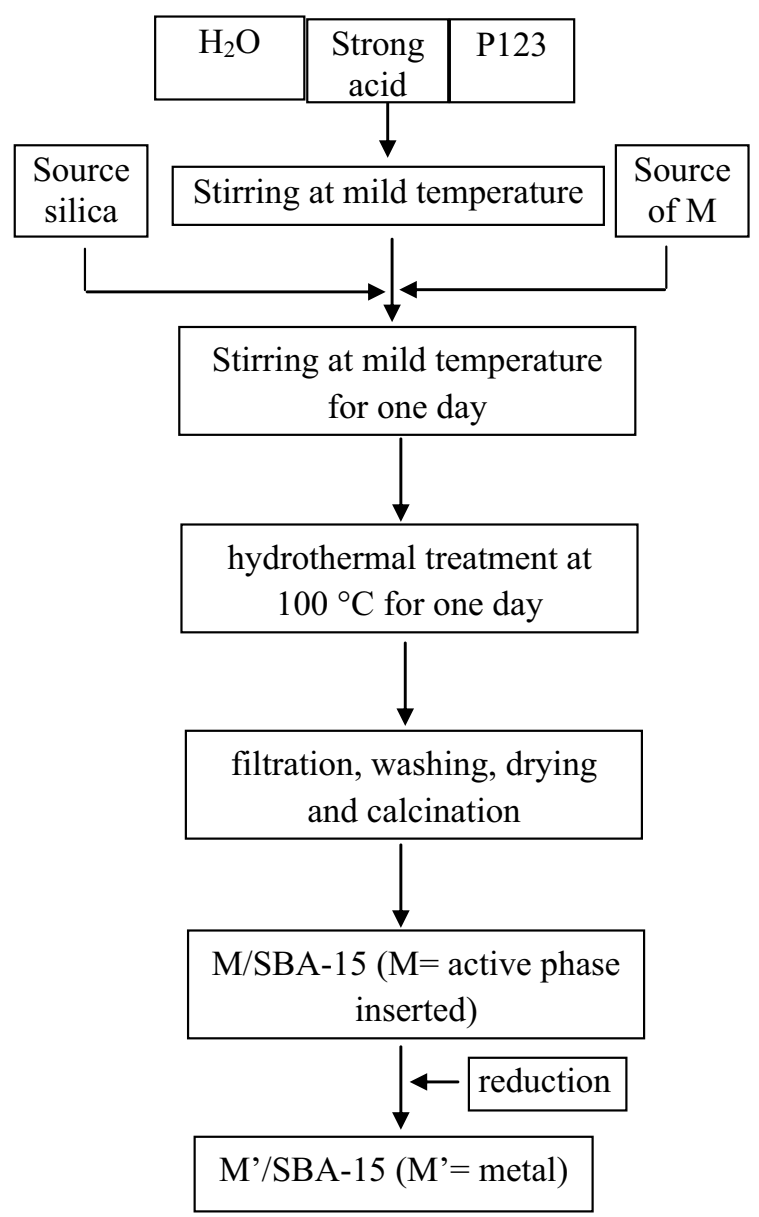


comparison to direct synthesis is the high percentage of impregnation of the components in the active sites, the values approach or even exceed the estimated theoretical percentage without destroying the support mesostructure [59-61]. Despite the mentioned advantages, the post synthesis method presents some drawbacks, such as: production of non-uniform materials due to evaporation process that leads to the migration of the material from the pores to the surface [58]; reduction of surface area, pore volume, pore diameter [25,59-61]; dependence on the nature of the solvent to ensure adequate distribution and dispersion of the particles in the carrier [43]; and oxidation of transition metal oxides giving low heteroatom dispersion [62]. It is difficult to obtain an adequate interaction between the precursor species of the heteroatom and the surface silane groups of the support $[46,63,64]$. Table 2 shows the effects of SBA-15 functionalization on textural properties by the direct synthesis and post-synthesis methods.

Table 2 shows that both methods affect the textural properties of SBA-15 support. The Si/M ratio is lower in the post-synthesis method, showing that this route promotes a greater insertion of the active phase in the support than the direct synthesis method. The decrease in texture properties (surface area, pore volume and pore diameter) is attributed to the presence of metal oxide within the mesoporous structure of the support [65]. The increase of the surface area as observed in the sample LaSBA-15 (synthesis II) can occur owing the larger surface area of mesopore ascribed to the enhancement long-range arrangement of structure of support. Addition of the precursor source of sites actives might to favor the mentioned the long-range arrangement of structure of support [65].

The incorporation of metal may also alter the lattice parameter in a unit cell, when occurs substitution of the short $\mathrm{Si}-\mathrm{O}$ bond by a longer $\mathrm{M}-\mathrm{O}$ bond, and expansion occurs in the unit cell evidenced by the displacement of the peaks at low angles in the $\operatorname{XRD}[65,66]$.

\subsection{Deposition-precipitation (DP) method}

This technique was developed to gain catalysts with welldispersed metal or metal oxide on the surface of the support. It is based on the solubility of the cations intended for deposition in the carrier, generally if the cation chosen for deposition in the carrier is precipitable, the respective catalyst may be manufactured by the deposition-precipitation method [14, 67-71].

This method involves dissolution of the precursor source of the metal by adjusting the $\mathrm{pH}$ to ensure complete precipitation of the metal generally in hydroxide form which is deposited on the surface of the support (SBA-15) followed by filtration, washing, drying and calcination which decomposes the precipitated hydroxide into oxides, water and undesirable residues. The $\mathrm{pH}$ control of the solution is a crucial factor because the precipitation of the metal depends on the $\mathrm{pH}$. The deposition of nanoparticles involves three steps: supersaturation, nucleation and particle growth of the precipitate on the surface of the support. Nucleation can be controlled by the slow and homogeneous introduction of the precipitating agent. The hydrolysis of urea at $90^{\circ} \mathrm{C}$ provides a slow and homogeneous increase in $\mathrm{pH}[14,72-76]$. Scheme 2 shows the main steps deposition-precipitation (DP) and graft hybrid (GH) methods, respectively.

The main advantage of this route of synthesis is the obtaining of supported catalysts with high deposition rate of the active phase formed by small particles highly dispersed. The filtration step removes the chloride ions from the precursor source of the metal, avoiding interference in the catalytic reaction [14]. However, this methodology presents the difficulty of obtaining particles of specific uniform size to a particular application, because a wide distribution of particles occurs due to low control of their growth $[76,77]$. In addition, some reported procedures require the excessive use of reducing agent, such as $\mathrm{NaBH}_{4}$ (sodium borohydride) and $\mathrm{H}_{2}$, to ensure the formation of nanoparticle of the metal in the support, needing to be removed after the reaction [76]. The methodology is complex, requiring the control of some parameters that interfere in the formation of the precipitate: $\mathrm{pH}$, time and temperature [14].

Chirieac et al. [12] synthesized SBA-15 with copper and nickel by methods: incipient wetness impregnation followed by mild drying and partially extracted (IWI-MD/ EC), Precipitation with $\mathrm{Na}_{2} \mathrm{CO}_{3}$ (sodium carbonate) (P) and Precipitation with urea (DP). IWI-MD/EC method promoted greater interaction of the support with the active phase than the others. Method (DP) caused a partial collapse
Table 2 Effects of SBA-15 functionalization on textural properties direct synthesis and post-synthesis methods

\begin{tabular}{lllllllll}
\hline Synthesis & Samples & Si/M mix & Si/M product & $\mathrm{S}_{\mathrm{BET}}\left(\mathrm{m}^{2} \mathrm{~g}^{-1}\right)$ & $\mathrm{Vp}\left(\mathrm{cm}^{3} \mathrm{~g}^{-1}\right)$ & $\mathrm{Dp}(\mathrm{nm})$ & Method & Refs. \\
\hline I & SBA-15 & - & - & 883 & 1.01 & 5.90 & PS & [65] \\
& LaSBA-15 & 20 & 62 & 545 & 0.889 & 3.30 & & \\
$\mathrm{II}$ & SBA-15 & - & - & 362 & - & 7.05 & DS & [66] \\
& LaSBA-15 & 20 & 81.3 & 798 & - & 6.4 & & \\
\hline
\end{tabular}

Mix* Mixture 
Scheme 2 Main steps of SBA-15 functionalization by deposition-precipitation (DP) and graft hybrid $(\mathrm{GH})$ methods, respectively [14]

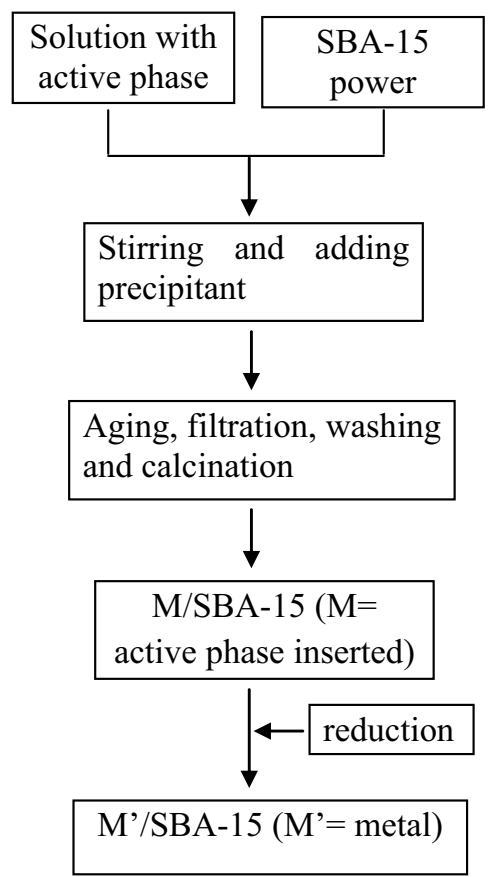

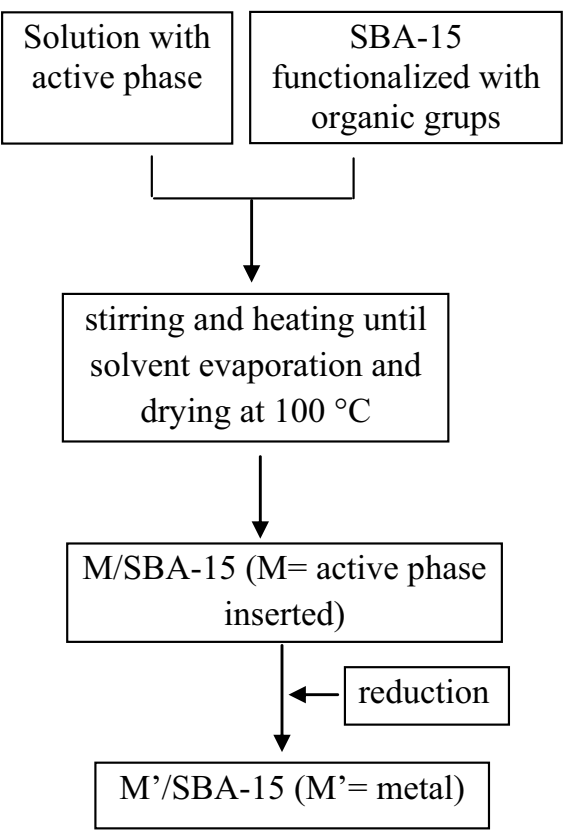

in the ordered mesoporous structure, evidenced by the absence in the low angle diffractograms of the reflections (210) and (300), reflection reduction (100) and shifted to lower values $2 \theta$. Similar result was reported by other authors and attributed to partial dissolution of the silica wall, in harsh conditions such as, $\mathrm{pH}$ and temperature [12, 78].

\subsection{Graft hybrid (GH) method}

The principle of this method is based on electrostatic interaction. The general steps involve: the functionalization of the previously prepared support (for example SBA-15) in the pores/surface by the insertion of organic groups; solubilization of the precursor source of the metal; mixing the functionalized support with the solution containing the precursor source of the metal to promote the interaction of the opposites between the functionalized groups and the metal cation followed by washing, drying, calcination and reduction $[14,48]$.

The literature reports the preparation of $\mathrm{Ag} / \mathrm{SBA}-15$ [51], Pt/SBA-15 [14, 48] and Au/SBA-15 [79] by the grafting method. In the case of Pt/SBA-15, SBA-15 support was pretreated in water for $1 \mathrm{~h}$ under reflux, followed by heating at $150^{\circ} \mathrm{C}$ under vacuum. Pre-treated SBA- 15 was suspended in toluene and $\mathrm{N}$-trimethoxysilypropyl- $\mathrm{N}, \mathrm{N}$-trimethylammonium chloride (TPTAC, $50 \mathrm{wt} \%$ in methanol) was added. The mixture was stirred at $80^{\circ} \mathrm{C}$ for $6 \mathrm{~h}$. The obtained sample was washed with toluene and ethanol and dried. SBA15 functionalized with TPTAC (TPTAC-SBA-15) was blended with ethanol solution containing hexachloroplatinic(IV) acid hexahydrate $\left(\mathrm{H}_{2} \mathrm{PtCl}_{6}\right)$. After 10 min the solid was washed with ethanol, dried at room temperature and finally reduced in hydrogen flow at $100-300^{\circ} \mathrm{C}$ to get Pt/ SBA-15 GH.

Graft Hybrid (GH) method has the advantage of adjusting the amount of functionalized organic groups, pore structures and amount of charged metal. However, the textural properties: surface area, volume and pore size decrease significantly suggesting that the pores of support are blocked and/or nanoparticles do metal are attached on the channels of support $[14,48,80]$.

\subsection{Colloid immobilization method}

This method consists in the use of a dendrimer to encapsulate the metal nanoparticles prior to be deposited on the carrier. In brief, the method involves the following steps: choosing a suitable dendrimer to interact with the solution of the precursor source of the metal; mixing the solutions of the precursor source of the metal and source of the dendrimer; reduction of the metal by the $\mathrm{NaBH}_{4}$ reducing agent; immobilization of the nanoparticles in the support by ultrasound; separation of nanoparticles followed by drying. The separation step is by centrifugation or evaporation system [14, 50-53]. Scheme 3 shows the main steps colloid immobilization $(\mathrm{Cl})$ and nanoparticles encapsulation (NE) methods, respectively.

The reduction step is very important, so it is necessary to select the most suitable reducing agent in minimizing the particle size, the literature points out $\mathrm{NaBH}_{4}$ as more efficient than $\mathrm{H}_{2}$, alcohol, glycol and ethylene glycol. 
Scheme 3 Main steps of SBA15 functionalization by colloid immobilization $(\mathrm{Cl})$ and nanoparticles encapsulation (NE) methods, respectively $[14,55]$
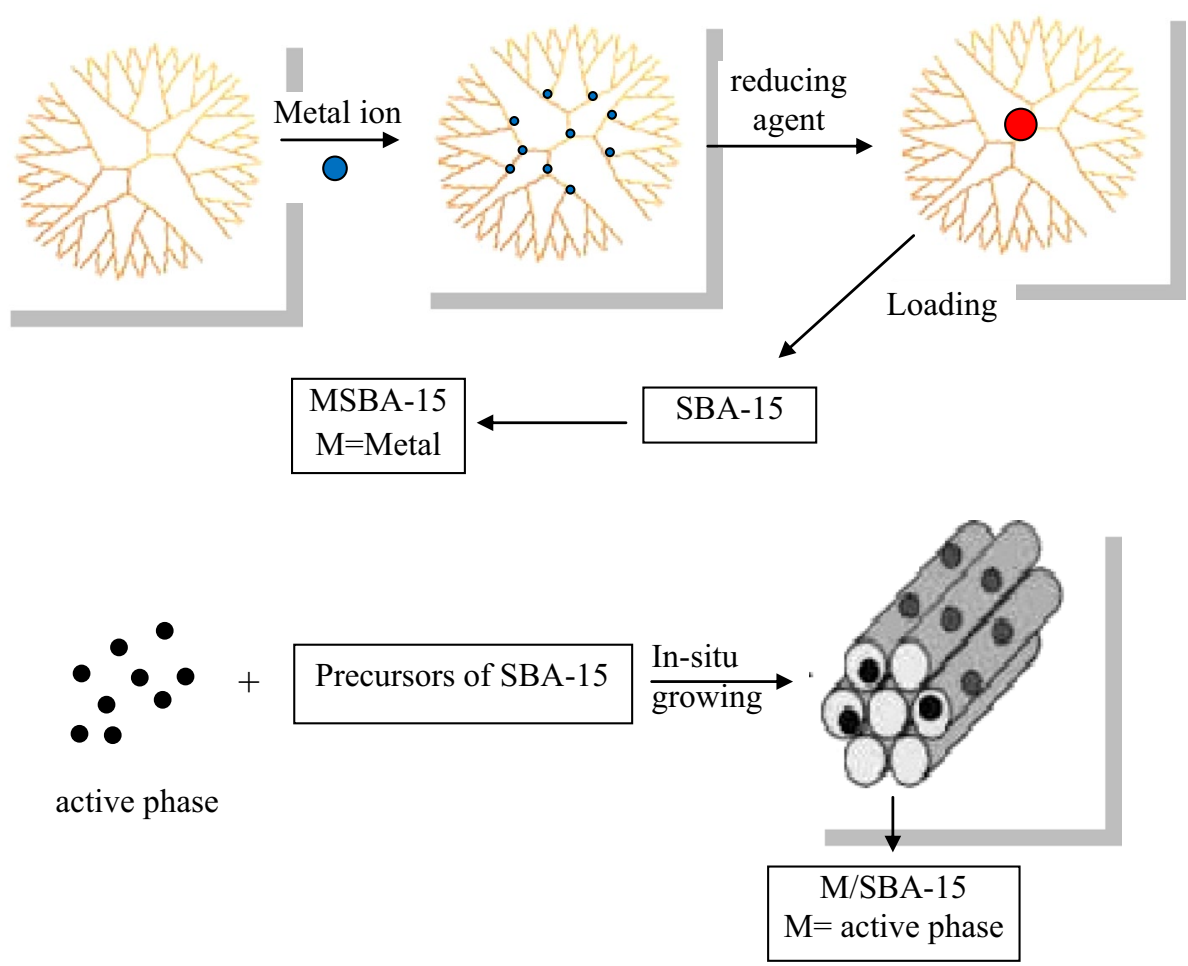

[81-85]. Advantage is in controlling the size of the nanoparticles and avoiding the pre-dispersion in the support [85-87]. However, this method has some disadvantages: the challenge of obtaining nanoparticles from the active phase to be introduced in the support; low yield of nanoparticles due to incomplete reduction of precursor ions [88]; long calcination time to remove the stabilizing agent from the nanoparticles $[55,89]$.

\subsection{Nanoparticle encapsulation method}

Also called the inclusion method, the previously synthesized nanoparticles are included in the synthesis gel during the formation of the support. This method includes the following steps: synthesis of the nanoparticles to be deposited on the support; addition of the nanoparticles in the SBA-15 synthesis gel; continued synthesis of SBA-15, namely, aging of the synthesis gel, hydrothermal treatment, lapping, drying and calcinations $[54,55]$.

The literature reports the synthesis of catalysts supported in SBA-15 using this method $[54,55]$ which show that the presence of the nanoparticles does not interfere in the formation of SBA-15. In this method, nanoparticles are stabilized in the support and present sizes similar to the initial one and allows the deposition on the support without the necessity of synthesizing it separately. However, there are some challenges, such as: difficulty into get nanoparticles from the active phase introduced in the SBA-15 and keeping them stable in the acid medium
$(\mathrm{pH} \sim 1)$ of the SBA-15 synthesis gel and at high calcination temperatures used to remove the triblock copolymer P123.

The summary of the discussion of the conventional SBA-15 functionalization methods described in this review is presented in Table 3, which summarizes the main characteristics of the methods described in items 2.2-2.6, facilitating the comparison in the synthesis steps, advantages and disadvantages of the methods described in this review.

\subsection{Alternative routes of functionalization of SBA-15}

The methods described (items 2.1-2.6) provide SBA-15 catalysts functionalized with various metal oxides, but have some disadvantages. Thus, some changes in the synthesis methods have been made to overcome the drawbacks. $\mathrm{TiO}_{2} / \mathrm{SBA}-15$ was obtained by altering the route of the direct synthesis method by introducing the $\mathrm{TiO}_{2}$ nanoparticles on the SBA-15 synthesis gel before the silica source, this method called an anchor in situ (ISA) by the authors $[61,90]$. Li et al. [10] reported a synthesis route with two templates for Al-Ce-SBA-15 to overcome the problem of metal agglomeration. This methodology provided SBA15 functionalized with $\mathrm{Al}$ and Ce highly dispersed on the surface, narrow pore distribution with surface area and volume of pores respectively $773 \mathrm{~m}^{2} \mathrm{~g}^{-1}$ and $0.87 \mathrm{~cm}^{3} \mathrm{~g}^{-1}$ ). 


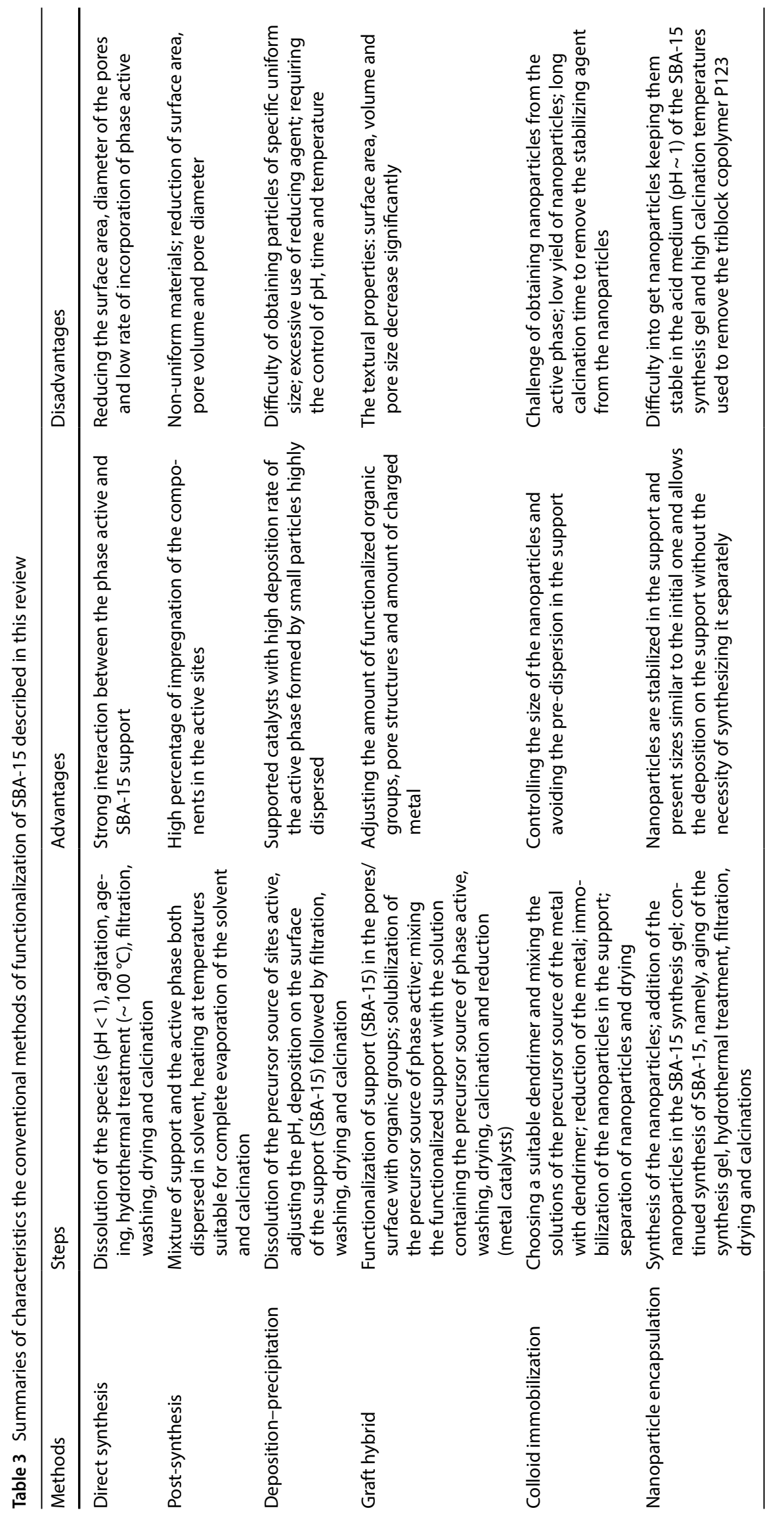


Another change in the route of the direct synthesis method is the adjustment of $\mathrm{pH}$, because under very acidic conditions such as the synthesis of SBA-15 the metals are very soluble. This methodology is important to incorporate metal oxides that are strongly affected by the $\mathrm{pH}$ of the SBA-15 synthesis gel. The literature reports SBA-15 functionalized by this strategy, such as: Co-SBA-15 [15], La-SBA-15 [66, 91], Fe-SBA-15]33] and Ga/SBA-15 [20].

Chirieac et al. [12] modified the post-synthesis method to obtain SBA-15 functionalized with copper and nickel. The modification consisted of using SBA-15 with partially extracted surfactant, by solvent extraction, use of SBA-15 occluded with P123 was shown to be a good strategy to obtain high dispersion of the $\mathrm{Ni}$ and $\mathrm{Cu}$ nanoparticles on the internal surface of SBA-15 maintaining the textural properties of mesoporous materials. Chi et al. [92] report novel method to fabricated Ag/SBA-15 with well dispersed silver nanoparticles inside the mesoporous channels silica, using incipient wetness impregnation method, toluene as fill agent, $\mathrm{Ag}\left(\mathrm{NH}_{3}\right)_{2} \mathrm{NO}_{3}$ solution as source of silver and glucose how mild reducing agent. Prashar et al. [93] obtained PtSBA-15 with nanoparticles of Pt inside mesoporous channels of SBA-15 using novel in situ template method which was similar to the direct synthesis method adding CTAB surfactant on the synthesis gel.

Functionalization of SBA-15 can potentiate the applications in several fields: catalysis, adsorption, separation. The conventional methods of direct synthesis, post-synthesis, deposition-precipitation, graft hybrid, colloid immobilization and nanoparticle encapsulation, as well as new functionalization routes have provided SBA-15 functionalized with several active phases (metal, metal oxides, organic groups). Despite the advances in the fabrication of functionalized SBA-15, the challenge of obtaining SBA15 functionalized while maintaining the properties of the support (SBA-15) and the active phase still remains. The current challenges are to functionalize the SBA-15 with unstable inorganic materials at the $\mathrm{pH}$ of obtaining the SBA-15 $(\mathrm{pH}<1)$, inserting active sites phases in the pores of the SBA-15. Thus, strategies such as: obtaining SBA-15 at less acidic $\mathrm{pH}(\mathrm{pH} \sim 5)$, increasing the pore diameters of SBA-15, as well as reducing the particle size of the active phase to be inserted into the support should be investigated and to provide more advances in the area of catalysis and materials.

\section{Choosing the best method for functionalization SBA-15}

The selection of the most suitable method depends on the application of the catalyst and the type of metal or metal oxide to be introduced into the SBA-15. The application in catalysis, such as: hydrogenation, oxidation of volatile organic compounds depend on the surface area of the support, dispersion of active sites and particle size. The literature indicates that high surface area, good dispersion of active sites and small particles are responsible for high catalytic activity $[94,95]$. So if application will be in these reactions should select the method that favors these properties.

The type of metal or metal oxide to be inserted influences the choice since some metal cations such as $\mathrm{Al}$ and $\mathrm{Ga}$ are very soluble in acidic medium synthesis of SBA-15 $(\mathrm{pH} \sim 1)$, limiting the insertion of metal cations. In this case, the direct synthesis method is not indicated.

Some articles influence the synthesis methods on the performance of the catalysts: Chirieac et al. [12] functionalized SBA- 15 with $\mathrm{Cu}$ and $\mathrm{Ni}$ by wet incipient impregnation methods followed by mild conditions; Precipitation with $\mathrm{Na}_{2} \mathrm{CO}_{3}$ and precipitation with urea. Catalyst obtained by the wet incipient impregnation method has high activity ( $100 \%$ in conversion in $120 \mathrm{~min}$ ) for the hydrogenation of cinnamaldehyde. VOx/SBA-15 obtained by the postsynthesis method (impregnation) showed good selectivity and conversion to methane oxidation [9]. Zu et al. [95] Synthesized Pt/SBA-15 by the Nanoparticle (NE) encapsulation method and applied them to $\mathrm{CO}$ oxidation, obtaining a satisfactory result suggesting that $\mathrm{Pt} / \mathrm{SBA}-15$ by the NE method is a good catalyst for CO oxidation with good thermal stability.

\section{Conclusion}

Functionalization of SBA-15 support is of great interest of the scientific community, the main methods described in this brief review are most commonly used for this purpose. There are advantages and challenges in all methods described here. Direct synthesis (DS) method promotes strong interaction between the support and the inserted active phase. The post-synthesis method (PS) has high efficiency in the incorporation of the species to be introduced in the support and avoids the problem of solubility of metal cations in acidic medium $(\mathrm{pH} \sim 1)$ present in the direct synthesis method. The direct synthesis and postsynthesis methods are the most used. Deposition-precipitation method (DP) provides high deposition rate of the well-dispersed active phase formed by small particles. Graft Hybrid (GH) method has the advantage of adjusting the amount of functionalized organic groups, pore structures and amount of charged metal. Colloid Immobilization $(\mathrm{Cl})$ method controls the size of the nanoparticles and prevents pre-dispersion in the carrier. Nanoparticle Encapsulation (NE) method allows stabilization of the particles in the carrier maintaining the initial size and eliminates 
a step of synthesis (impregnation). Despite the benefits already mentioned, these methods alter the textural properties of the SBA-15 support, reducing the surface area, average pore diameter and pore volume. They do not provide SBA-15 functionalized with all desirable features at the same time, such as: textural properties very similar to those of SBA-15, efficient active phase insertion, particle size control and particle distribution. The alternative to overcome these difficulties in the described methods has been the change in the routes of the mentioned methods. The choice of method must be based on the application of the catalyst and the properties of the active phase to be inserted in the support.

\section{Compliance with ethical standards}

Conflict of interest On behalf of all authors, the corresponding author states that there is no conflict of interest.

\section{References}

1. Corma A (1997) From microporous to mesoporous molecular sieve materials and their use in catalysis. Chem Rev 97:2373-2420

2. Zholobenko VL, Khodakov AY, Impéror-Clerc M, Durand D, Grillo I (2008) Initial stages of SBA-15 synthesis: an overview. Adv Colloid Interface Sci 42:67-74

3. Vernimmen J, Meynen V, Cool P (2011) Synthesis and catalytic applications of combined zeolitic;mesoporous materials. Beilstein J Nanotechnol 2:785-811

4. Chaudhary V, Sharma S (2017) An overview of ordered mesoporous material SBA-15: synthesis, functionalization and application in oxidation reactions. J Porous Mater 24:741-749

5. El-Nahhal IM, Salem JK, Selmane M, Kodeh F, Ebtihan HA (2017) Synthesis and structural characterization of $\mathrm{ZnO}$ and $\mathrm{CuO}$ nanoparticles supported mesoporous sílica SBA-15. Chem Phys Lett 667:165-171

6. Yang G, Deng Y, Wang J (2014) Non-hydrotermal synthesis and characterization of MCM-41 mesoporous materials from iron ore tailing. Ceram Int 40:7401-7746

7. Cai C, Wang H, Han J (2011) Synthesis and characterization of ionic liquid-functionalized alumino-silicate MCM-41 hybrid mesoporous materials. Appl Surf Sci 257:9802-9808

8. Yang H, Deng Y, Du C, Jin S (2010) Novel synthesis of ordered mesoporous materials Al-MCM-41 from bentonite. Appl Clay Sci 47:351-355

9. Wallis P, Wohlrab S, Kalevaru VN, Frank M, Martin A (2016) Impact of support pore structure and morphology on catalyst performance of VOx/SBA-15 for selective methane oxidation. Catal Today 278:120-126

10. Li M, Liu N, Wu Z, Li S, Xu W, Luo Z, Liu Y (2016) A facile and novel route for dual-template method synthesis of mesoporous siica material Al-Ce-SBA-15. Mater Lett 185:85-88

11. Zhao D, Feng J, Huo Q, Melosh N, Fredrickson GH, Chmelka BF, Stucky GD (1998) Triblock copolymer syntheses of mesoporous silica with periodic 50 to 300 angstrom pores. Pores Sci 279:548-552

12. Chirieac A, Dragoi B, Ungureanu A, Ciotonea C, Mazilu I, Royer S, Mamede AS, Rombi E, Ferino I, Dumitriu E (2016) Facile synthesis dispersed and thermally stable copper-based nanoparticles supported on SBA-15 occluded with P123 surfactant for catalytic applications. J Catal 339:270-283

13. Yang C-M, Zibrowius B, Schmidt W, Schuth F (2004) Stepwise removal of the copolymer template from mesopores and micropores in SBA-15. Chem Mater 16(15):2918-2925

14. Zhu J, Wang T, Xu X, Xião P, Li J (2013) Pt nanoparticles supported on SBA-15: synthesis, characterization, and applications in heterogeneous catalysis. Appl Catal B 130(131):197-217

15. Lou Z, Wang R, Sun H, Chen Y, Yang Y (2008) Direct synthesis of highly ordered Co-SBA-15 mesoporous materials by the $\mathrm{pH}$-adjusting approach. Microporous Mesoporous Mater 110:347-354

16. Gildo SP, Schwark DW, Thomas EL, Gonçalves MC (1993) Observation of a non-constat mean curvature interface in an $A B C$ triblock copolymer. Macromolecules 26:2636-2640

17. Zhao D, Huo Q, Feng J, Chmelka BF, Stucky GD (1998) Nonionic triblock and star diblock copolymer and oligomeric surfactant syntheses of highly ordered, hydrothermally stable, mesoporous silica strutures. J Am Chem Soc 120:6024-6036

18. Tsoncheva T, Santo VD, Gallo A, Scotti N, Dimitrov M, Kovacheva D (2011) Structure and catalytic activity of hosted in mesoporous silicas copper species: effect of preparation procedure and support pore topology. Appl Catal A 406:13-21

19. Cabrera-Munguia DA, González H, Gutiérrez-Alejandre A, Rico JL, Huirache-Acuña R, Mava-Yescas R, Del Rio RE (2017) Heterogeneous acid conversion of a tricaprylin-palmitic acid mixture over AI-SBA-15 catalysts: reaction study for biodiesel synthesis. Catal Today 282:195-203

20. Selvaraj M, Kawi S (2008) Direct synthesis and catalytic performance of ultralarge pore GaSBA-15 mesoporous molecular sieves with high gallium content. Catal Today 131:82-89

21. Han Y, Kim H, Park J, Lee S, Kim J (2012) Influence of Ti doping level on hydrogen adsorption of mesoporous Ti-SBA-15 materials prepared by direct synthesis. Int J Hydrog Energy 37:14240-14247

22. Shahbazi A, Younesi H, Badiei A (2014) Functionalized nanostructured silica by tetradentate-amine chelating ligand as efficient heavy metals adsorbent: applications to industrial effluent treatment. Korean J Chem Eng 31:1598-1607

23. Shahbazi A, Younesi $H$, Badiei A (2013) Batch and fixed-bed column adsorption of $\mathrm{Cu}(\mathrm{II}), \mathrm{Pb}$ (II) and $\mathrm{Cd}$ (II) from aqueous solution onto functionalised SBA-15 mesoporous silica. Can J Chem Eng 91:739-750

24. Cashin VB, Eldridge DS, Yu A, Zhao D (2018) Surface functionalization and manipulation of mesoporous silica adsorbents for improved removal of pollutants: a review. Environ Sci Water Res Technol 4:110-128

25. Rahmat N, Abdullah AZ, Mohamed AR (2010) A review: mesoporous santa barbara amorphous-15, types, synthesis and its applications towards biorefinery production. Am J Appl Sci 7:1579-1586

26. Slowing II, Vivero-Escoto JL, Wu CW, Lin VSY (2008) Mesoporous silica nanoparticles as controlled release drug delivery and gene transfection carriers. Adv Drug Deliv Rev 60:1278-1288

27. Kim S-N, Ko SA, Lee SH, Huh BK, Choy YB (2018) Amine-grafted SBA-15 for ophthalmic delivery of dexamethasone. J Solid State Chem 268(102-107):27

28. Thunyaratchatanon $C$, Luengnaruemitchai $A$, Chaisuwan T, Chollacoop N, Chen S-Y, Yoshimura Y (2017) Synthesis and characterization of $\mathrm{Zr}$ incorporation into highly ordered mesostructured SBA-15 material and its performance for $\mathrm{CO}_{2}$ adsorption. Microporous Mesoporous Mater 253:18-28

29. Mitran G, Ahmed R, Iro E, Hajimirzaee S, Hodgson S, Urdã A, Olea M, Marcu I-C (2018) Propane oxidative dehydrogenation over VOx/SBA-15 catalysts. Catal Today 306:260-267 
30. Feliczak-Guzik A, Wawrzynczak A, Nowak I (2015) Selective catalytic oxidations of cyclohexene, thioether and geraniol with hydrogen peroxide. Sensitivity to the structure of mesoporous niobosilicates. Microporous Mesoporous Mater 202:80-89

31. Selvaraj M, Park W, Kawi S, Kim I (2012) Selective synthesis of benzophenone over two-dimensional mesostructured CrSBA15. Appl Catal A 415:17-21

32. Kim J, Ichikuni N, Hara T, Shimazu S (2016) Study on the selectivity of propane photo-oxidation reaction on SBA-15 supporte Mo oxide catalyst. Catal Today 265:90-94

33. Yan H, Chen W, Liao G, Li X, Ma S, Li L (2016) Activity assessment of direct synthesized Fe-SBA-15 for catalytic ozonation of oxalic acid. Sep Purif Technol 159:1-6

34. Shen $H, W u X$, Jiang $D$, Li X, Ni J (2017) Identification of active sites forhydrogenation over Ru/SBA-15 using in situ Fouriertransform infrared spectroscopy. Chin J Catal 38:1597-1602

35. Wu Z, Zhang L, Guan Q, Fu M, Ye D, Wu T (2015) Catalytic oxidation of toluene over Au-Co supported on SBA-15. Mater Res Bull 70:567-572

36. Dai P, Zhang L, Zhang G, Li G, Sun Z, Liu X, Wu M (2014) Characterization and photocatalytic activity of ( $\mathrm{ZnO}-\mathrm{CuO}) \mathrm{SBA}-15$ nanocomposites synthesized by two-solvent method. Mater Res Bull 56:119-124

37. Li B, Xu Z, Chu W, Luo S, Jing F (2017) Ordered mesoporous SnSBA-15 as support for Pt catalyst with enhanced performance in propane dehydrogenation. Chin J Catal 38:726-735

38. Han P, Wang X, Qiu X, Ji X, Gao L (2007) One-step synthesis of palladium/SBA-15 nanocomposites and its catalytic application. J Mol Catal A: Chem 272:136-141

39. Han J, Fang P, Jiang W, Li L, Guo R (2012) Ag-nanoparticlesloaded mesoporops silica: spontaneous formation of Ag nanoparticles and mesoporous silica SBA-15 by a one-pot strategy and their catalytic applications. Langmuir 28:4768-4775

40. Peng K, Li X, Liu X, Wang Y (2017) Hydrothermally stable Nb-SBA-15 catalysts applied in carbohydrate conversion to 5-hydroxymethyl furfural. Mol Catal 441:72-80

41. Luz GE Jr, Lima SH, Melo ACR, Araujo AS, Fernandes VJ Jr (2010) Direct synthesis and characterization of LaSBA-15 mesoporous molecular sieves. J Mater Sci 45:1117-1122

42. Rivoira L, Martínez ML, Anunziata O, Beltramone A (2017) Vanadium oxide supported on mesoporous SBA-15 modified with $\mathrm{Al}$ and $\mathrm{Ga}$ as a highly active catalyst in the ODS of DBT. Microporous Mesoporous Mater 254:96-113

43. Lee S-S, Park H-I, Park N-K, Byeon S-H (2006) Influence of solvents on the formation of Pd and PdO nanoparticles in SBA15. Mater Sci Eng, B 135:20-24

44. Zienkiewicz-Strzałka M, Pasieczna-Patkowska S, Kozak M, Pikus S (2013) Silver nanoparticles incorporated onto ordered mesoporous silica from Tollen's reagent. Appl Surf Sci 266:337-343

45. Chytil S, Glomm WR, Kvande I, Tiejum Z, Blekkan EA (2006) Platinum nanoparticles incorporated in mesoporous silica SBA-15 by the deposition-precipitation method. Stud Surf Sci Catal 162:513-520

46. Chytil S, Glomm WR, Blekkan EA (2009) Characterization of Pt/SBA-15 prepared by the deposition-precipitation method. Catal Today 147:217-223

47. Chytil S, Glomm WR, Kvande I, Zhao T, Walmsley J, Blekkan EA (2007) Platinum incorporated into the SBA-15 mesostructure via deposition $=$ precipitation method: Pt nanoparticle size estimation and catalytic testing. Top Catal 45:93-99

48. Yang CM, Liu PH, Ho YF, Chiu CY, Chao KJ (2003) Highly dispersed metal nanoparticles in functionalized SBA-15. Chem Mater 15:275-280
49. Zhang LX, Shi JL, Yu J, Hua ZL, Zhao XG, Ruan ML (2002) A new in situ reduction route for the synthesis of Pt nanoclusters in the channels of mesoporous silica SBA-15. Adv Mater 14:1510-1513

50. Huang W, Kuhn JN, Zhang Y, Habas SE, Yang P, Somorjai GA (2008) Dendrimer templated synthesis of one nanometer Rh and Pt particles supported on mesoporous silica: catalytic activity for ethylene and pyrrole hydrogenation. Nano Lett 8(7):2027-2034

51. Molnar É, Konya Z, Tasi G, Kirics I (2005) IR spectroscopic investigation of the particle size and morphology of platinum nanoparticles supported on mesoporous silicate. Stud Surf Sci Catal 15:1351-1358

52. Nemanashi-Maumela M, Nongwe I, Motene RC, Davids BL, Meijboom R (2017) Au and Ag nanoparticles encapsulated within sílica nanospheres using dendrimers as dual templating agent and their catalytic activity. Mol Catal 438:184-196

53. Li H, Lu J, Zheng Z, Cao R (2011) An efficient and reusable silica/ dendrimer supported platinum catalyst for electron transfer reactions. J Colloid Interface Sci 353:149-155

54. ParkY Kang T, Kim P, Yi J (2006) Encapsulation method for the dispersion of $\mathrm{NiO}$ onto ordered mesoporous silica, SBA-15, using polyethylene oxide (PEO). J Colloid Interface Sci 295:464-471

55. Song H, Rioux RM, Hoefelmeyer JD, Komor R, Niesz K, Grass $M$, Yang P, Somorjai GA (2006) Hydrothermal growth of mesoporous SBA-15 Silica in the presence of PVP-stabilized Pt nanoparticles: synthesis, characterization, and catalytic properties. J Am Chem Soc 128:3027-3037

56. Prathap MUA, Kaur B, Srivastava R (2012) Direct synthesis of metal oxide incorporated mesoporous SBA-15, and their applications in non-enzymatic sensing of glucose. J Colloid Interface Sci 381:143-151

57. Bérubé $F$, Khadraoui A, Florek J, Kaliaguine S, Kleitz F (2015) A generalized method toward high dispersion of transition metals in large pore mesoporous metal oxide/silica hybrids. J Colloid Interface Sci 449:102-114

58. Ciola R (1981) Fundamentos da Catálise. Moderna, São Paulo

59. Zhang Q, Wang M, Zhang T, Wang Y, Tang X, Ning P (2015) A stable Ni/SBA- 15 catalyst prepared by the ammonia evaporation method for dry reforming of methane. RSC Adv 5:94016-94024

60. Vargas-Hernández D, Rubio-Caballero JM, Santamaría-González J, Moreno-Tost R, Mérida-Robles JM, Pérez-Cruz MA, JiménezLópez A, Hernández-Huesca R, Maireles-Torres P (2014) Furfuryl alcohol from furfural hydrogenation over copper supported on SBA-15 silica catalysts. J Mol Catal A: Chem 383:106-113

61. Salameh C, Nogier JP, Launay F, Boutros M (2015) Dispersion of colloidal $\mathrm{TiO}_{2}$ nanoparticles on mesoporous materials targeting photocatalysis applications. Catal Today 257:35-40

62. Martinez A, López C, Marquez F, Diaz I (2003) Fischer-Tropsch synthesis of hydrocarbons over mesoporous Co/SBA-15 catalysts: the influence of metal loading, cobalt precursor, and promoters. J Catal 220:486-499

63. Kim T-W, Kim M-J, Kleitz F, Nair MM, Guillet-Nicolas R, Jeong K-W, Chae H-J, Kim C-U, Jeong S-Y (2012) Tailor-made mesoporous Ti-SBA-15 catalysts for oxidative desulfurization of refractory aromatic sulfur compounds in transport fuel. ChemCatChem Catal 4:687-697

64. Bérubé F, Khadraoui A, Janicke MT, Kleitz F, Kaliaguine S (2010) Optimizing silica synthesis for the preparation of mesoporous TiSBA-15 epoxidation catalysts. Ind Eng Chem Res 49:6977-6985

65. Bendahou K, Cherif L, Siffert S, Tidahy HL, Benaissa H, Aboukais $A$ (2008) The effect of the use of lanthanum-doped mesoporous SBA-15 on the performance of Pt/SBA-15 and Pd/SBA-15 catalysts for total oxidation of toluene. Appl Catal A 351:82-87

66. Mu Z, Li JJ, Hao ZP, Qiao SZ (2008) Direct synthesis of lanthanidecontaining SBA-15 under weak acidic conditions and its catalytic study. Microporous Mesoporous Mater 113:72-80 
67. Bezemer GL, Radstake PB, Koot V, van Dillen AJ, Geus W, Jong KP (2006) Preparation of Fischer-Tropsch cobalt catalysts supported on carbon nanofibers and silica using homogeneous deposition-precipitation. J Catal 237:291-302

68. Hermans LAM, Geus JW (1979) Interaction of nickel ions with silica supports during deposition-precipitation. Stud Surf Sci Catal 3:113-130

69. Burattin $\mathrm{P}, \mathrm{Che} M$, Louis C (1998) Molecular approach to the mechanism of deposition-precipitation of the $\mathrm{Ni}(\mathrm{II})$ phase on silica. J Phys Chem B 102:2722-2732

70. Burattin P, Che M, Louis C (1997) Characterization of the Ni(II) phase formed on silica upon deposition-precipitation. J Phys Chem B 101:7060-7074

71. De Jong KP (1991) Deposition precipitation onto pre-shaped carrier bodies. possibilities and limitations. Stud Surf Sci Catal 63:19-36

72. Munnik P, Jongh PE, De Jong KP (2015) Recent developments in the synthesis of supported catalysts. Chem Rev 115:6687-6718

73. Akolekar DB, Bhargava SK, Foran G, Takahashi M (2005) Studies on gold nanoparticles supported on iron, cobalto, manganese, and cerium oxide catalytic materials. J Mol Catal A: Chem 238:78-87

74. Centeno MA, Portales C, Carrizosa I, Odriozola JA (2005) Gold supported $\mathrm{CeO}_{2} / \mathrm{Al}_{2} \mathrm{O}_{3}$ catalysts for $\mathrm{CO}$ oxidation: influence of the ceria phase. Catal Lett 102:289-297

75. Daté M, Okumura M, Tsubota S, Haruta M (2004) Vital role of moisture in the catalytic activity of supported gold nanoparticles. Angew Chem 116:2181-2184

76. Campelo JM, Luna D, Luque R, Marinas JM, Romero AA (2009) Sustainable preparation of supported metal nanoparticles and their applications in catalysis. Chemsuschem 2:18-45

77. Cushing BL, Kolesnichenko VL, O'Connor CJ (2004) Recent advances in the liquid-phase syntheses of inorganic nanoparticles. Chem Rev 104:3893-3946

78. Ciotonea C, Dragoi B, Ungureanu A, Chirieac A, Petit S, Royer $S$, Dumitriu E (2013) Nanosized transition metals in controlled environments of phyllosilicate-mesoporous silica composites as highly thermostable and active catalysts. Chem Commun 49:7665-7667

79. Lee Y, Ma Z, Zhang Z, Park C, Daí S (2009) Influences of synthesis conditions and mesoporous structures on the gold nanoparticles supported on mesoporous silica hosts. Microporous Mesoporous Mater 122:160-167

80. Yang CM, Sheu HS, Chao KJ (2002) Templated Synthesis and structural study of densely packed metal nanostructures in MCM-41 and MCM-48. Adv Funct Mater 12:142-148

81. Wang T, Shou H, Kou Y, Liu H (2009) Base-free aqueous-phase oxidation of non-activated alcohols with molecular oxygen on soluble Pt nanoparticles. Green Chem 11:562-568

82. Ahmadi TS, Wang ZL, Green TC, Henglein A, El-Sayed MA (1996) Shape-controlled synthesis of colloidal platinum nanoparticles. Science 272:1924-1926
83. Rioux RM, Song H, Hoefelmeyer JD, Yang P, Somorjai GA (2005) High-surface-area catalyst design: synthesis, characterization, and reaction studies of platinum nanoparticles in mesoporous SBA-15 silica. J Phys Chem B 109:2192-2202

84. Yamada YMA, Arakawa T, Hocke H, Uozumi Y (2007) A nanoplatinum catalyst for aerobic oxidation of alcohols in water. Angew Chem Int Ed 46:704-706

85. Wang T, Xião C-X, Yan L, Xu L, Luo J, Shou H, Kou Y, Liu H (2007) Aqueous-phase aerobic oxidation of alcohols by soluble Pt nanoclusters in the absebce of base. Chem Commun 2007:4375-4377

86. Porta F, Prati L, Rossi M, Coluccia S, Martra G (2000) Metal sols as a useful tool for heterogeneous gold catalyst preparation: reinvestigation of a liquid phase oxidation. Catal Today 61:165-172

87. Grunwaldt JD, Kiener C, Wogerbauer C, Baiker A (1999) Preparation of supported gold catalysts for low-temperature $\mathrm{CO}$ oxidation via "size-controlled" gold colloids. J Catal 181:223-232

88. Hossain MJ, Tsunoyama H, Yamauchi M, Ichikuni N, Tsuuda T (2012) High-yield synthesis of PVP-stabilized small Pt clusters by microfluidic method. Catal Today 183:101-107

89. Lang H, May RA, Iverson BL, Chandler BD (2003) Dendrimerencapsulated nanoparticle precursors to supported platinum catalysts. J Am Chem Soc 125:14832-14836

90. Araújo MM, Silva LKR, Sczancoski JC, Orlandi MO, Longo E, Santos AGD, Santos RS, Luz GE Jr, Cavalcante LS (2016) Anatase $\mathrm{TiO}_{2}$ nanocrystals anchored at inside of SBA-15 mesopores and their optical behavior. Appl Surf Sci 389:1137-1147

91. Luz GE Jr, Santos AGD, Melo ACR, Oliveira RM, Araujo AS, Fernandes VJ Jr (2011) Thermal catalytic cracking of buriti oil (Mauritia flexuosa $\mathrm{L}$ ) over LaS15 mesoporous materials. Fuel Process Technol 92:2099-2104

92. Chi Y, Zhao L, Yuan Q, Li Y, Zhang J, Tu J, Li N, Li X (2012) Facile encapsulation of monodispersed silver nanoparticles in mesoporous compounds. Chem Eng J 195(196):254-260

93. Prashar AK, Hodgkins RP, Chandran JN, Rajamohanan PR, Devi RN (2010) In situ encapsulation of Pt nanoarchitectures of varying morphologies in mesoporous compounds. Chem Mater 22:1633-1639

94. Li X, Zheng W, Pan H, Yu Y, Chen L, Wu P (2013) Pt nanoparticles on highly dispersed TiO2 coated on SBA-15 as an efficient and recyclable catalyst for liquid-phase hydrogenation. J Catal 300:9-19

95. Zhu J, Xie X, Carabineiro SAC, Tavares PB, Figueiredo JL, Schomacker R, Thomas A (2011) Facile one-pot synthesis of Pt nanoparticles SBA-15: an active and stable material for catalytic applications. Energy Environ Sci 4:2020-2024

Publisher's Note Springer Nature remains neutral with regard to jurisdictional claims in published maps and institutional affiliations. 